(c) American Dairy Science Association, 2006.

\title{
Major Advances in Our Understanding of Nutritional Influences on Bovine Health
}

\author{
J. P. Goff \\ National Animal Disease Center, USDA-Agricultural Research Service, Ames, IA 50010
}

\begin{abstract}
The Journal of Dairy Science has increasingly become a primary outlet for scientific research concerning the health of the dairy cow and her calf. This paper attempts to highlight Journal of Dairy Science articles that have linked nutrition and nutritional strategies to reduce disease incidence on the dairy farm. Disorders associated with an animal's inability to cope with the demands of high production include diseases such as milk fever and ketosis, which clearly are related to the cow's inability to maintain bodily functions in the face of negative calcium or energy balance. Improved nutrition of the late gestation cow can reduce the incidence of some of these disorders. Susceptibility to infectious disease is dependent on the integrity of the immune system, and recent studies have shed light on nutritional factors that affect leukocyte function. Other disorders, such as retained fetal membranes, udder edema, and displacement of the abomasum are not easily categorized as to their cause, but nutritional strategies have been developed to help prevent these disorders as well.
\end{abstract}

Key words: immunology, metabolic disease, milk fever, ketosis

\section{INTRODUCTION}

Although articles examining the effects of nutrition and management on milk production remain a Journal of Dairy Science standard, papers concerning the effects nutrition can have, for better or worse, on the health of the dairy cow and calf are increasingly common. When cattle become unhealthy (or die), they quickly become unprofitable. More importantly, the public expects the milk cow and her calf to be well cared for and healthy. A healthy calf is a calf that grows well and is free of disease. A healthy cow produces profitable amounts of milk, is capable of reproducing, and is free of disease, both infectious and metabolic. Some disorders, such as

Received October 25, 2004.

Accepted April 4, 2005.

E-mail: jgoff@nadc.ars.usda.gov milk fever and ketosis, are related to the cow's inability to maintain bodily functions in the face of negative calcium or energy balance, and there is a clear effect of nutrition on the susceptibility to these disorders. Malnutrition clearly influences the ability of the immune system to function, which affects the incidence of diseases such as mastitis, Salmonellosis, and metritis.

The properly functioning immune system does 3 things well. 1) It recognizes and eliminates foreign invaders such as bacteria, viruses, and parasites. 2) It recognizes and does not initiate attacks on the tissues of the body. 3) In the case of the female, the immune system must also recognize and then tolerate the presence of sperm and a fetus within the reproductive tract to allow successful reproduction. In the September 1971 issue of the Journal of Dairy Science, a symposium entitled "Bovine Immune System" was published, highlighting the state of the knowledge of bovine immunology at the time. Looking back at the papers now it is interesting to note that nearly all the scientific work focused on the role of antibody as an index of disease resistance. Cell-mediated immunity was not yet on the radar screen. This presentation will try to highlight some of the advances made in our understanding of the interaction between nutrition and bovine metabolic and infectious disease resistance using the scientific knowledge described in the 1971 symposium as the starting point.

To help put health issues in perspective in the US dairy industry, Table 1 summarizes data from the 1996 and 2001 National Animal Health Monitoring System (NAHMS) reports. Mastitis remains the number one health problem of the dairy cow, followed by lameness, and retained fetal membranes. Keeping in mind that it is statistically invalid to compare data in the 2 surveys, it is interesting to note that over the $6 \mathrm{yr}$ between the 2 surveys, it would appear that we have not made great gains in preventing these 3 disorders; in fact, the incidence of these disorders may be on the rise. More disturbing from the surveys is a $25 \%$ increase in the incidence of displaced abomasum over the 6-yr period. The only disease with a decreasing incidence was clinical milk fever, which may reflect research leading to a better understanding of the causes of milk fever. It is 
Table 1. Incidence of major health problems in US dairy herds in 1995 and 2001 as a percentage of total number of dairy cows or calves (modified from the 1996 and 2002 NAHMS surveys)

\begin{tabular}{lrr}
\hline & \multicolumn{2}{c}{ Cattle affected, \% } \\
\cline { 2 - 3 } & 1995 & 2001 \\
\hline Mastitis & 13.4 & 14.7 \\
Lameness & 10.5 & 11.6 \\
Retained fetal membranes & 7.8 & 7.8 \\
Milk fever & 5.9 & 5.2 \\
Abomasal displacement & 2.8 & 3.5 \\
Heifers dying before weaning & 10.8 & 8.7 \\
\hline
\end{tabular}

also very disturbing that 1 in 11 heifer calves born alive in 2001 failed to survive to weaning, though some solace may be had by noting that this is a big improvement over 1995, when nearly 1 in 9 heifer calves born alive failed to survive until weaning.

The published research from the last quarter-century that will be highlighted in this presentation shares the common characteristics of providing major insight into the etiology of a health problem in dairy cows or calves or providing a practical means of resolving these problems on dairy farms. The insight provided by some of these papers was not recognized until many years later. It will be interesting to see what other hidden gems emerge over the next few years from papers already published in the Journal of Dairy Science. I briefly discuss a few papers that I think fit into the 'hidden gem' category.

\section{Effects of Nutrition on Immune Function and Disease Resistance of the Growing Calf}

The newborn calf is devoid of protective antibodies in its bloodstream because maternal immunoglobulins do not cross the placenta in the bovine. Nature solved this problem using colostrum, the first secretion of the mammary gland after giving birth. Colostrum should contain large amounts of immunoglobulin. The antibodies are generally directed against the pathogens the cow succeeded in fending off during her lifetime. Ingestion of colostrum in the first hours after birth allows effective transfer of maternal antibody to the calf's circulation and provides immediate protection from septicemic disease caused by many bacteria and viruses. Absorption of colostral immunoglobulin represents a unique aspect to nutrition of the calf vital to the health of the calf on a dairy. Papers in the 1971 Journal of Dairy Science symposium recognized the importance of colostrum as a source of immunoglobulin for the calf but also recognized that nearly $30 \%$ of calves fed colostrum failed to have adequate levels of protective antibody in their blood following colostrum ingestion. Experiments conducted after 1971 helped describe the subtleties of colos- trum biology, which explained why failure of passive transfer of antibody was occurring in such a large proportion of calves. University of Arizona studies led by Stott determined that the age of the calf when colostrum was fed affected antibody absorption. Other studies demonstrated that breed, age of the cow (older cows had better colostrum), and quantity of first milk (the more secretion obtained at first milking, the lower the quality) affected colostrum quality.

How nutrition of the newborn calf affects disease resistance is very poorly understood. Numerous papers have addressed the effects that inclusion of antibiotics and coccidiostats had on health of the calf, but the nutrition of the calf and the subsequent disease resistance and health of the calf were largely ignored. In general, it is assumed that if growth is good, health must be good. When calves were fed diets supplying less protein and energy than was required to obtain growth, death loss also was higher. However, recently there has been a movement toward increasing the protein and sometimes the energy content of milk replacers (and/or starter rations) to obtain growth that is "accelerated" over that obtained with more traditional milk replacers, which are about $20 \%$ protein and $20 \%$ fat. These intensified diets do cause calves to grow faster although there is considerable debate as to whether the quick early growth translates into a more profitable cow. These diets might still be worth feeding if they improved disease resistance of the calves and a recent study by Nonnecke and coworkers demonstrated that feeding milk replacer with higher concentrations of fat and energy influenced some in vitro measures of immune function; some positively, some negatively. One problem with this and similar studies is that we do not necessarily know if these in vitro assays of cell function translate into real disease resistance in the calf. Also, the advantage in immune function, if there is one, may only become manifest in calves that are challenged with a disease. For instance, the extra body reserves of a calf on an "intensified diet" may allow that animal to rebound from disease faster or be able to mount an immune response for a longer time than a traditionally fed calf. Unfortunately, these studies are expensive and until they are conducted, we cannot fully answer these questions.

Although effects of protein and energy on the immune response have not been addressed well in the calf, the role that vitamins and trace minerals have on health of the calf has been examined numerous times. Frank (and in some cases, marginal) deficiencies of any of the required vitamins or minerals affect calf health and often the immune system of these animals is impaired. Research published during the last $25 \mathrm{yr}$ reported that various measures of immune function were improved 
when calves were supplemented with certain trace minerals or vitamins. In some studies, control animals were fed diets considered deficient, but in other studies such as those conducted by Gengelbach and Spears at North Carolina State University and Reddy and colleagues at Kansas State University, the control diet provided adequate amounts of the nutrient in question based on accepted standards of the time. Traditionally, nutrient requirements were based entirely on growth or other production performance measures. These more recent studies are important in that they allow some measure of an immune parameter to be considered when determining the requirement of an animal for a nutrient. Much more work needs to be done in this arena to determine whether nutrient requirements as set forth in publications such as the 2001 NRC Nutrient Requirements of Dairy Cattle accurately reflect the needs of the immune system. On the other hand, research has shown that overzealous supplementation of certain vitamins and trace minerals can impair immune function. For example, Nonnecke and colleagues demonstrated that dairy calves supplemented with high amounts of vitamin A (rates commonly found in milk replacers when the research was published) had reduced vitamin $\mathrm{E}$ status and impaired lymphocyte function suggestive of a less competent immune system.

Hidden Gem? Recently, Muscato and colleagues at Cornell determined that adding as little as $8 \mathrm{~mL}$ of rumen fluid to milk replacer increased weight gain and reduced incidence of scours in calves. Because autoclaved rumen fluid was as effective as fresh rumen fluid, the authors suggested that some factor(s), such as bacterial polysaccharide, in rumen fluid had stimulated the immune system of the calf. Obviously, the ban on "ruminant to ruminant" feeding blocks feeding rumen fluid as used in this study but if the active component can be identified, we may have a powerful tool to help prevent disease in calves.

\section{Effects of Nutrition on Immune Function and Disease Resistance of the Adult Cow}

As in calves, frank deficiency of any required nutrient impairs growth and health of the cow and simply adding the missing nutrient to the diet can solve the problem. However, providing proper nutrition to the periparturient cow can be more challenging. Dry matter intake, and subsequently nutrient intake, is reduced greatly a few days before calving and remains low for a few days after calving. At the same time, requirements for nutrients are increased because of colostrum synthesis and events associated with parturition. During this period, cows are usually in severe negative energy balance and serum or plasma concentrations of several minerals and vitamins are reduced, suggesting lowered status. This period often represents a time when the immune system of the cow is severely suppressed, making cows particularly vulnerable to infectious diseases such as mastitis. Why cows are so immunosuppressed around the time of calving is not clear, but it does appear that the metabolic challenges associated with the onset of lactation are factors capable of affecting immune function.

Studies have demonstrated that the initiation of lactation and milk synthesis is a factor contributing to immunosuppression in the recently calved cow. Scientists at the USDA-National Animal Disease Center studied neutrophil and lymphocyte functions during the weeks before and after calving in cows that were mastectomized, compared with those of cows that were intact and producing milk. Lymphocyte functions were greatly reduced in milk-producing cows, especially in the days immediately around calving. Neutrophil function declined in both intact and mastectomized cows as calving approached, but rebounded very quickly in mastectomized cows after calving. Neutrophil function remained depressed for several weeks after calving in milk-producing cows. The implication of this study was that the metabolic challenges experienced by the dairy cow at the onset of milk production impaired immune cell function.

\section{Retained Fetal Membranes, Mastitis, and Nutritional Immunology?}

The failure to expel the fetal membranes following parturition affects nearly $8 \%$ of dairy cows each year. A substantial body of work at The Ohio State University, initiated by Smith and Conrad and continued over the last 3 decades, has demonstrated that low dietary selenium or vitamin $\mathrm{E}$ is associated with a high incidence of mastitis and retained fetal membranes and that supplementation with both Se and vitamin $\mathrm{E}$ (in the diet or via intramuscular injection) greatly reduced the incidence of both retained fetal membranes and mastitis in affected herds. Deficiencies of Se and/or vitamin E impair neutrophil function, which could explain resistance of cows to mastitis following Se/vitamin E supplementation. Studies at other institutions confirm and extend the Ohio State work. A recent paper examined neutrophil function in late gestation cows and provided evidence that if a cow's neutrophils were functioning poorly before calving, that cow was likely to have retained fetal membranes. Studies also demonstrate that inadequate antioxidant status or "oxidative stress" of the cow contributes to a poorly functioning immune system and increases the risk of mastitis as well as retained fetal membranes. Addition of vitamin $\mathrm{E}$ or $\beta$ carotene may improve antioxidant status, which im- 
proves immune function, reducing the incidence of retained fetal membranes and mastitis. An important feature of many of these experiments is that the control diets, based on requirement standards in use when the experiments were conducted, were thought to provide an adequate amount of the nutrient examined. This emphasizes the need to continually reevaluate nutrient standards using multiple response variables to determine nutrient requirements.

Many studies have examined neutrophil, lymphocyte, and monocyte function by in vitro "testing". Unfortunately, we have little data to actually document that improved "neutrophil iodination" or " $\gamma$-interferon production by lymphocytes" actually translates into improved disease resistance. The gold standard when evaluating the effects of a nutrient on animal immune capabilities is a properly designed and conducted challenge with a pathogen. An example of a well-designed experiment to determine the influence of nutrition on health was conducted at the University of Kentucky by Scaletti and colleagues. This paper demonstrates a wonderful model for testing whether a nutritional intervention truly increases resistance against a disease. In their model, cows were fed either a copperdeficient or a copper-replete diet during lactation. The animals were then challenged with 22 cfu of Escherichia coli infused into one quarter of the mammary gland. Bacterial growth in the milk and the severity of mastitis, as assessed by somatic cell score and rectal temperature, was more severe in the copper-deficient cows. The beauty of this model is that the animals were challenged with a realistic dose of bacteria, which allowed them to demonstrate that the cows with the stronger immune systems overcame the challenge, whereas cows with a weakened immune system did not fare as well. Too often challenge models in the literature have used excessively large numbers of bacteria (or virus) administered to the animal, often by unnatural routes (such as intravenous injection), to experimentally "infect" the animal. These challenges are often so great that the immune system is unlikely to successfully deal with the challenge, no matter how strong it is. Many more studies designed along the lines of the Kentucky study may allow us to verify which in vitro tests of immune function truly are indicative of immune status of the cow, so that pathogenic challenges would not be necessary.

Hidden Gem? A 1997 report from the Ohio State group demonstrated a profound reduction in mastitis in cows that were heavily supplemented with vitamin $\mathrm{E}$ before calving and in early lactation. Cows were assigned to 1 of 3 treatments. The diet of cows in the first group was supplemented with $100 \mathrm{IU}$ of vitamin $\mathrm{E}$ before calving and $100 \mathrm{IU}$ of vitamin $\mathrm{E}$ during the first weeks of lactation. The second treatment consisted of $1000 \mathrm{IU}$ of vitamin $\mathrm{E}$ before and $500 \mathrm{IU}$ of vitamin $\mathrm{E}$ after calving (i.e., essentially the requirement set forth recently by the NRC). The third group received 4000 IU of vitamin E before calving and 2000 IU of vitamin $\mathrm{E}$ in early lactation. The incidence of mastitis in any quarter of these cows during that lactation was 25,17 , and $3 \%$ in the 3 groups respectively. Some criticize this study because it was performed with a diet Se concentration of $0.1 \mathrm{mg} / \mathrm{kg}$ of DM and that, if the legal limit of Se had been fed $(0.3 \mathrm{mg} / \mathrm{kg}$ of $\mathrm{DM})$, the results might not have been so dramatic. However, it may also be argued that if just 2 cases of mastitis per 100 cows in a herd were prevented as a result of increased vitamin $\mathrm{E}$ supplementation during this relatively short period, the cost of the vitamin $\mathrm{E}$ would be well justified.

\section{Metabolic Diseases of the Dairy Cow}

As research is solidifying the connection between metabolic disease and impaired immune function leading to infectious disease, it seems more prudent than ever to do all that we can to reduce metabolic disease in the dairy cow (Figure 1). To make matters worse, numerous epidemiological studies clearly demonstrate that a cow with one metabolic disorder, such as milk fever, is at much greater risk of developing a second metabolic disorder, such as ketosis, than a cow that did not have any metabolic disease.

Lactation imposes tremendous metabolic demands on the dairy cow. The adaptation to these demands at the onset of lactation, coinciding with the birth of the calf, can overwhelm the ability of some cows to cope, leading to breakdowns in metabolism of the cow. The failure to adequately fuel the body during lactation can lead to fatty liver and ketosis. The inability to maintain sufficient concentrations of calcium in the blood to allow normal bodily functions can cause periparturient hypocalcemic paresis, more commonly known as milk fever. Early lactation is often associated with other common noninfectious disorders such as displacement of the abomasum and rumen acidosis. Advances in our understanding of each of the common metabolic diseases of dairy cows have been published in the Journal of Dairy Science.

\section{Milk Fever}

Milk fever occurs when calcium leaves the blood to support milk production faster than Ca can be put back into the blood from the diet, skeletal Ca stores, and renal conservation of calcium. The disease is characterized by an acute decline in blood $\mathrm{Ca}$ concentration to levels that no longer support nerve and muscle function. The result is a weak cow that is unable to contract 


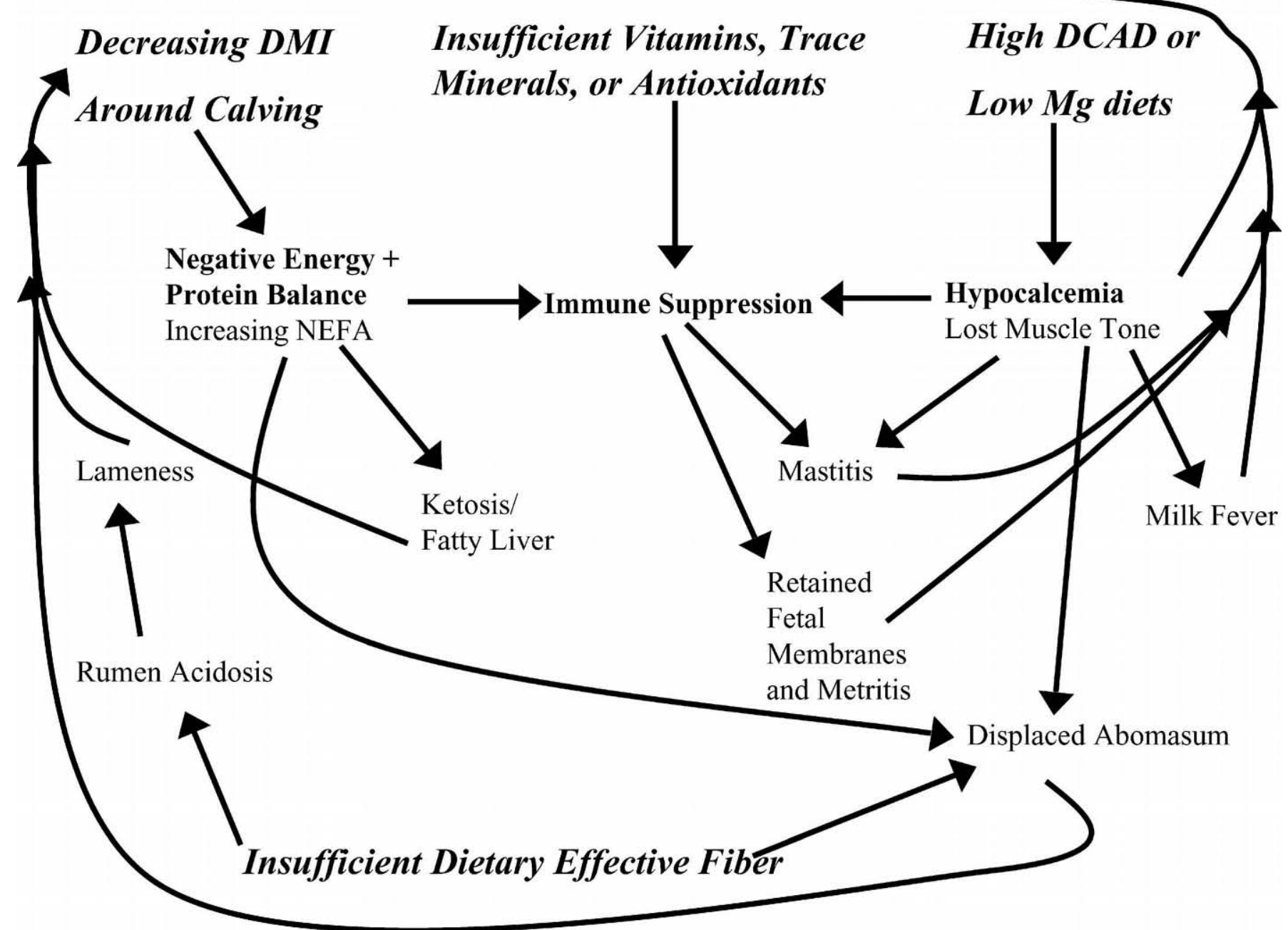

Figure 1. Interrelationships between nutrition and disease in the periparturient dairy cow. Key dietary factors are italicized, and key metabolic functions are in bold type.

smooth muscles (such as those responsible for abomasal contraction and closure of the teat sphincter) or skeletal muscle properly, which can result in a cow that is unable to stand. In most cows, the mammary drain of calcium from the blood causes only a minor decline in blood calcium because these cows respond to the developing hypocalcemia by secreting parathyroid hormone (PTH), which then activates cells to resorb calcium from bone, enhance renal reabsorption of calcium from glomerular filtrate, and begin renal production of the hormone 1,25-dihydroxyvitamin D necessary for efficient intestinal calcium absorption. These calcium homeostatic mechanisms fail to operate sufficiently in some cows, resulting in the milk fever condition.

Throughout the 1960s and 1970s the prevailing theory was that milk fever was caused by high calcium diets fed before calving, which were thought to cause a shutdown of parathyroid gland activity during the dry period. The inactive parathyroid gland was thought to be too sluggish to successfully stimulate mobilization of enough calcium from the bone and diet to prevent milk fever. Research conducted in the 1970s and early 1980s added credence to this theory by demonstrating that low calcium diets prevented milk fever by stimulating the parathyroid gland to release PTH for several weeks before calving. This caused bone calcium resorption and renal production of 1,25-dihydroxyvitamin D before calving so that at the onset of lactation, those mechanisms were already primed to meet the calcium demands of lactation. Feeding a "low calcium" diet to dry cows remained the strategy for milk fever prevention in the United States and much of the world until 
1984, despite the fact that most farms were incapable of getting diet calcium levels low enough to truly stimulate parathyroid gland activity.

In 1984, Block evaluated the hypothesis put forward by Ender and Dishington, the Norwegian scientists who demonstrated milk fever could be prevented by feeding cows forages preserved with hydrochloric and sulfuric acids or by adding certain salts of these acids to the diet of the dry cow. Block fed late-gestation dairy cows a diet that contained an excess of anions (supplied by salts such as calcium chloride, aluminum sulfate, and magnesium sulfate) or a diet that contained an excess of cations (supplied by sodium carbonate and sodium bicarbonate). Cows consuming the diet with added anions had no milk fever, but $47 \%$ of cows consuming the cationic diet developed milk fever. Not only that, but cows fed the anionic diet before calving produced nearly $7 \%$ more milk in the subsequent lactation than cows fed the cationic diet before calving.

These results resurrected the Norwegian hypothesis, which, unfortunately, had been largely relegated to obscurity. They also spurred on further studies, which corroborated and refined these observations. Additional studies identified alternative (and more palatable) anion supplements, developed practical on-farm methods of monitoring whether diets were effective (i.e., measuring urine $\mathrm{pH}$ ), and provided information on the mode of action of anionic diets.

Still, the 2 strategies for milk fever prevention failed to explain the root cause of milk fever. A 1997 study conducted at the USDA's National Animal Disease Center suggested that metabolic alkalosis, induced by high $\mathrm{K}$ or Na diets reduced PTH responsiveness of bone and kidney tissues, causing an inability of the cow to maintain adequate blood calcium concentrations. High calcium diets fed to the cows did not cause milk fever, suggesting that the older theory - that dietary Ca inhibits PTH secretion and responsiveness causing milk fever-was invalid. Thus, milk fever occurs secondary to metabolic alkalosis induced by diets high in cations such as $\mathrm{K}$ or Na. We still can use the strategy of feeding very low calcium diets (essentially a calcium-deficient diet supplying much less absorbable calcium than the cow requires) to trick the parathyroid gland into secreting PTH before calving. This works because prolonged exposure of tissues to elevated PTH levels can overcome tissue resistance to PTH that might be induced by a high $\mathrm{K}$ diet. Unfortunately, these calcium-deficient diets are often difficult to formulate.

Another key to milk fever prevention deserves mention. A body of work by European workers such as Martens in Germany and Van't Klooster, Beynen, and Schonewille of the Netherlands demonstrated that hypomagnesemia will also cause a breakdown in PTH action and calcium homeostasis, which could lead to milk fever. Fortunately these workers have also demonstrated that high levels of magnesium supplementation can overcome factors such as high diet $\mathrm{K}$ that prevent efficient magnesium absorption across the rumen.

Hidden Gem? It can be difficult to formulate a low $\mathrm{K}$ diet or add appropriate anions to the diet to properly acidify the cow for milk fever control. Low calcium diets offer an alternative but are difficult to formulate. Jorgensen and colleagues in Denmark recently demonstrated that sodium aluminum silicate (zeolite A) could be added to diets that may not be quite low enough in calcium to effectively stimulate PTH secretion. The zeolite A binds enough calcium in the diet to reduce the absorption of calcium so that it effectively stimulates calcium homeostatic mechanisms before calving and prevents hypocalcemia.

\section{Ketosis/Fatty Liver Complex}

Ketosis, as described in a 1982 review by Baird, generally occurs in cows 2 to 4 wk in lactation. Because the rapid increase in milk production after calving is not accompanied by a rapid rise in feed intake, all cows are in negative energy balance in early lactation. This forces them to draw on body fat to help meet energy needs of milk production. Unfortunately, if excessive, the release of NEFA from body fat overwhelms the capacity of the liver to use the fatty acids as fuel. They are instead converted to ketone bodies such as acetone, aceto-acetic acid, and $\beta$-hydroxybutyrate (BHBA). Blood glucose concentrations in clinically affected cows fall below the level required to support nerve and brain function and cows often exhibit stumbling while walking, head pressing, and other signs of central nervous system dysfunction. Ketotic cows also are inappetant, which further exacerbates their negative energy balance. Milk production falls precipitously (upsetting to the farmer, though this actually helps the cow cope with the negative energy balance situation). The type of ketosis described by Baird was readily cured by intravenous infusion of glucose, followed by the addition of energy in the form of grain to the diet. The literature at the time was largely influenced by European experiences with cows fed pasture-based diets low in nonfiber carbohydrate. However, since that time it has become clear that we are seeing a different kind of ketosis on US dairies. Though clinical symptoms are similar to classical ketosis, this form of ketosis is often occurring in cows less than $10 \mathrm{~d}$ in lactation and it can often be difficult to treat as it is generally accompanied by some degree of fatty liver in the cow. The etiology and control of this periparturient form of ketosis has been a focus for the last $25 \mathrm{yr}$. 
There had always been an association between fat build-up in the liver and ketosis. The prevailing idea was that prolonged release of fatty acids from adipose tissue eventually overwhelmed the capacity of the liver to oxidize them. At that point, the fatty acids were converted to triglycerides, which slowly accumulated in the liver and eventually disrupted liver function. Studies of experimental ketosis at Iowa State University, induced by restriction of feed and the addition of 1,3-butanediol to the diet (which the body converted to BHBA to simulate the elevated ketone bodies of natural ketosis), suggested the ketotic state was actually preceded by an increase in fat in the liver. Grummer and colleagues at the University of Wisconsin reported that feed intake is depressed by about $20 \%$ around the time of calving (i.e., a natural restriction in feed intake). This finding, new at the time, is now known to be rather typical-although management factors, metabolic disease, and diet can certainly make this situation better or worse. Simultaneous with the feed intake depression at calving, plasma NEFA and liver triglyceride concentrations exhibited their greatest increase. By including a treatment in which cows were force-fed by placing feed refusals into the rumen via a cannula, they showed that the depression in feed intake around the time of calving was largely responsible for the liver fat buildup. This study pointed out the need to maintain DM intake in the days immediately before and after calving to prevent periparturient ketosis. Interestingly, other studies have shown that severely restricting feed intake after the first 2 wk of lactation does not elicit a great increase in blood NEFA or liver fat content, suggesting other aspects of the physiology of the cow on the day of calving are confounding factors in development of periparturient ketosis.

If low DM intake at calving is a major predisposing factor for periparturient ketosis, the question arises as to how to feed the cow to minimize a decline in feed intake at calving. Two rather different approaches have been evaluated in an attempt to answer this question.

Minor and colleagues at the University of Wisconsin hypothesized that a diet with a high concentration of NFC would promote increased intake during late gestation. In their study, cows fed a diet with $44 \% \mathrm{NFC}$ consumed substantially more $\mathrm{DM}(+27 \%)$ and $\mathrm{NE}_{\mathrm{L}}$ $(+57 \%)$ during late gestation than did cows fed a more typical diet (24\% NFC). Cows fed the high NFC diet were in positive energy balance during the last few weeks of gestation whereas cows fed the typical diet were in slightly negative energy balance. Concentrations of NEFA and BHBA in plasma and concentrations of hepatic triglycerides were lower for cows fed the high NFC diet.
In stark contrast, a study by Holcomb and others at the University of Florida failed to find any advantage to high DM intake in late gestation, in and of itself, on milk production or health of cows. In their study there was even a slight tendency for cows whose feed intake had been restricted (60 to $80 \%$ of ad libitum intake) before calving to have higher feed intake and milk yield in early lactation compared with the cows fed ad libitum. This paper, along with several others, stimulated the argument that restricting the DM intake of the cows before calving prevented a major decline in feed intake at calving, as is commonly seen in cows fed ad libitum. It may be the degree of change in feed intake, not the actual amount of feed ingested, which triggers body fat mobilization at calving. Thus, high DM intake before calving may not necessarily be the goal of dry cow nutrition.

It also appears that cows that fail to adequately consume a certain number of calories during the day or two immediately before and after calving are at greatest risk of developing ketosis/fatty liver. Is maintenance of this critical level of energy intake during this relatively short period at calving best achieved by high NFC diets that promote high feed intake and more positive energy balance during the weeks before calving? Or is it better to limit calorie intake to the cow's maintenance and pregnancy requirements before calving (high roughage diets) to keep her "hungry" as she goes through the calving process so she is less likely to go off feed at calving? The answer awaits further research.

Feed additives to prevent ketosis in the dairy cows are of great interest. Supplying monensin, to shift rumen microbe populations and fermentation toward greater propionate production, via intraruminal controlled-release capsules has been shown by researchers at Guelph University to reduce the incidence of not only ketosis, but also of displacement of the abomasum and retained fetal membranes. Studies in which the monensin was added to the diet do not generally show the same promise. The rumen concentration of monensin may fall too low to be effective when DM intake declines around calving if the diet is supplying the monensin. The intraruminal capsule may deliver an effective dose of monensin, regardless of feed intake fluctuations.

Studies continue to ignite our interest in certain feed additives that show promise for the prevention of ketosis, but their effectiveness in follow-up research trials has often been less than hoped. Yet, there appear to be enough instances where these additives have helped to keep our hopes alive. For example, a number of experiments have reported positive effects on ketosis incidence and lipid transport when niacin or rumen-protected choline are fed to dry and fresh cows. 
Hidden Gem? Bauman's group at Cornell proposed to help the cow maintain energy balance in early lactation by decreasing the caloric demand of milk production in early lactation. They demonstrated that it was possible to significantly decrease the fat content of milk by feeding calcium salts of isomers of conjugated linoleic acid (CLA) to cows from 2 wk before calving through 20 wk of lactation. Feeding CLA reduced milk fat content by $12.5 \%$ during early lactation, so their first objective- to reduce the number of calories required to produce each liter of milk-was achieved. Unfortunately, the cows did not achieve better energy balance because the cows spent the energy savings by producing approximately $3 \mathrm{~kg} / \mathrm{d}$ more milk during the first $20 \mathrm{wk}$ of lactation. Postpartum concentrations of glucose, NEFA, and BHBA in plasma and hepatic content of glycogen and triglycerides were similar in control and CLAtreated cows. Despite the fact that this experimental approach did not solve the ketosis problem, it is a unique approach aimed at solving the ketosis problem.

\section{Udder Edema}

Experiments led by Hemken many years ago at the University of Kentucky demonstrated that addition of sodium or potassium to the diet of cows before calving can increase the incidence of udder edema in dairy cows. More recently, feeding anionic diets or diets with additional antioxidants have shown some promise in reducing udder edema. It is unfortunate that our knowledge of the causes of udder edema and the development of strategies to reduce its prevalence have progressed to such a limited degree.

\section{Displacement of the Abomasum}

Displacement of the abomasum occurs in approximately $3.5 \%$ of dairy cows each year (Table 1 ). The 1972 study led by Coppock at Texas A\&M was the first paper that clearly identified a nutritional risk factor for displacement of the abomasum. That study linked highconcentrate feeding in early lactation with development of left displaced abomasum. It has since become evident that abomasal displacement is a multifactorial disease with numerous nutritional risk factors. Cows exhibiting low feed intake during the peripartum period are at increased risk of displaced abomasum. Cows fed high concentrate to forage ratio diets in early lactation, diets that promote hypocalcemia, or diets with inadequate particle size are also at increased risk of having a displaced abomasum. Recent studies from Michigan State and Guelph are providing growing evidence that cows with elevated blood levels of NEFA before calving are at increased risk of developing left displacement of the abomasum, suggesting that prepartum diets as well as early lactation diets are contributing to abomasal displacement. These studies have spurred the use of prepartum blood NEFA determinations as a means of assessing herd susceptibility to other metabolic health problems such as ketosis as well.

\section{Rumen Acidosis}

Another metabolic disorder of the high-producing dairy cow is rumen acidosis. The need to increase calorie consumption to meet the energy demands of lactation has led to use of high-grain diets. Unfortunately, fermentation of these diets can cause a decline in rumen $\mathrm{pH}$, which, in extreme cases, can cause detrimental changes in microbial populations within the rumen. The etiology of rumen acidosis in the dairy cow appears to be different from the classical description of rumen acidosis observed in beef feedlot cattle. In feedlot cattle, the rapid production of lactic acid following an abrupt change to a high-starch diet causes rumen $\mathrm{pH}$ to fall dramatically, killing many rumen microbes, which then release endotoxins to the blood. As the lactic acid spills over into the blood, it causes severe metabolic acidosis in the animal, which acts with the endotoxemia to cause hypovolemic shock and often death.

Lactic acid production is not the hallmark of rumen acidosis in most dairy cattle. Instead, it is the total organic acid load induced by the diet, combined with the inability of the cow to buffer the organic acids with salivary secretions that causes rumen $\mathrm{pH}$ to fall. The simplest (although limited) approach to controlling rumen acidosis was the use of buffering agents such as sodium bicarbonate or alkalinizing agents such as magnesium oxide added to the ration. These had the added benefit of increasing milk fat in many cases, which will be discussed more fully in a companion paper in this issue (by Jenkins and McGuire). These buffering agents were first used in work led by Emery at Michigan State and Davis at Illinois in the early 1960s, and their use was refined by Penn State and Kentucky researchers during the 1970s and 1980s and are in common use in dairy rations today. The concept that dietary fiber contributes to chewing activity, production of saliva, and formation of the rumen raft was aptly described by Emery and colleagues at Michigan State in 1960 . Since that time, numerous studies published in the Journal of Dairy Science have led to better definition of the roles that particle length, rumen residency time, and fiber composition play in how "effective" dietary fiber is for promoting good rumination in the cow.

Lammers and others at Pennsylvania State University developed a practical means for on-farm assessment of the effective fiber content of forages and diets 
based on the particle size of the diet. It also allows prediction of selective eating patterns (i.e., sorting) of a diet. Ultimately, this tool became known as the Penn State Particle Separator and has allowed nutritionists to "shake out" rations to help reduce the risk of rumen acidosis and assist in trouble-shooting diets.

Another health concern affected by nutrition is laminitis, which is often a sequela of rumen acidosis. The prevailing notion, borrowed primarily from the equine world, is that endotoxemia following the death of microbes in the rumen causes circulatory changes in the foot, which can affect growth rate of cells in the corium layers and ultimately affects adhesion between these layers of the hoof wall, although direct experimental evidence of this phenomenon in cattle is lacking. Recent studies have demonstrated that supplementing diets of high-producing cows with biotin or zinc can reduce the incidence of laminitis lesions, presumably by strengthening the keratin bridges between wall and sole of the foot.

Hidden Gem? How we house the modern dairy cow can greatly influence her eating behavior and how she reacts to developing lameness. Cook and colleagues at Wisconsin recently reported on a study of sand-bedded vs. rubber crumb matting as a surface for free stalls for cows. Cows housed in sand-bedded free-stall barns exhibited significantly less lameness than cows in rubber mat-bedded free-stall barns. It also was evident that cows housed in free stalls bedded with rubber mats spent more time standing, which might be expected to aggravate separation of the layers of the hoof wall due to longer periods of pressure on the hoof wall. This study is important because these types of behavioral studies can give us clues to disease that ration formulation alone cannot. We need to spend more time examining the effects of housing, comfort, and care of cows in dairy herds on disease incidence and the response of cows to the diets they are offered.

\section{CONCLUSIONS}

The interrelationships between nutrition and disease in the periparturient cow can be quite complicated (Figure 1), and it becomes readily apparent that affliction with one metabolic disorder often initiates changes that predispose that animal to other metabolic and infectious diseases. Numerous salient reviews covering each of these diseases have been published in the Journal of Dairy Science since 1970 and should be the starting point for all students entering this field. Although great strides have been made in our understanding of the causes and nutritional strategies to prevent certain disorders such as milk fever, it is also apparent when we look at disease incidences over time that we lack effective strategies for prevention of disorders such as abomasal displacement and retained fetal membranes. Strategies to meet the energy needs of the cow in early lactation are varied and often seem at odds with each other. Further understanding of how cow comfort and facilities interact with nutrition of the close-up cow may clarify which strategies are most appropriate to prevent ketosis/fatty liver in dairy cows. Our understanding of nutritional immunology remains superficial. Reliable tools to assess the immune status of the cow must be developed and verified in challenge models to help us understand how nutrition can reduce susceptibility to diseases such as mastitis, metritis, and retained fetal membranes.

\section{REFERENCES}

Baird, G. D. 1982. Primary ketosis in the high-producing dairy cow: Clinical and subclinical disorders, treatment, prevention, and outlook. J. Dairy Sci. 65:1-10.

Bernal-Santos, G., J. W. Perfield, D. M. Barbano, D. E. Bauman, and T. R. Overton. 2003. Production responses of dairy cows to dietary supplementation with conjugated linoleic acid (CLA) during the transition period and early lactation. J. Dairy Sci. 86:3218-3228.

Bertics, S. J., R. R. Grummer, C. Cadorniga-Valino, and E. E. Stoddard. 1992. Effect of prepartum dry matter intake on liver triglyceride concentration and early lactation. J. Dairy Sci. 75:19141922.

Block, E. 1984. Manipulating dietary anions and cations for prepartum dairy cows to reduce incidence of milk fever. J. Dairy Sci. 67:2939-2948.

Brzezinska-Slebodzinska, E., J. K. Miller, J. D. Quigley, J. R. Moore, and F. C. Madsen. 1994. Antioxidant status of dairy cows supplemented prepartum with vitamin E and selenium. J. Dairy Sci. 77:3087-3095.

Cameron, R. E., P. B. Dyk, T. H. Herdt, J. B. Kaneene, R. Miller, H. F. Bucholtz, J. S. Liesman, M. J. Vandehaar, and R. S. Emery. 1998. Dry cow diet, management, and energy balance as risk factors for displaced abomasum in high producing dairy herds. J. Dairy Sci. 81:132-139.

Chew, B. P., L. L. Hollen, J. K. Hillers, and M. L. Herlugson. 1982. Relationship between vitamin A and beta-carotene in blood plasma and milk and mastitis in Holsteins. J. Dairy Sci. 65:2111-2118.

Cook, N. B., T. B. Bennett, and K. V. Nordlund. 2004. Effect of free stall surface on daily activity patterns in dairy cows with relevance to lameness prevalence. J. Dairy Sci. 87:2912-2922.

Coppock, C. E., C. H. Noller, S. A. Wolfe, C. J. Callahan, and J. S. Baker. 1972. Effect of forage-concentrate ratio in complete feeds fed ad libitum on feed intake prepartum and the occurrence of abomasal displacement in dairy cows. J. Dairy Sci. 55:783-789.

Curtis, C. R., H. N. Erb, C. J. Sniffen, R. D. Smith, and D. S. Kronfeld. 1985. Path analysis of dry period nutrition, postpartum metabolic and reproductive disorders, and mastitis in Holstein cows. J. Dairy Sci. 68:2347-2360.

Drackley, J. K., J. J. Veenhuizen, M. J. Richard, and J. W. Young. 1991. Metabolic changes in blood and liver of dairy cows during either feed restriction or administration of 1,3-butanediol. J. Dairy Sci. 74:4254-4264.

Duffield, T. F., D. Sandals, K. E. Leslie, K. Lissemore, B. W. McBride, J. H. Lumsden, P. Dick, and R. Bagg. 1998. Efficacy of monensin for the prevention of subclinical ketosis in lactating dairy cows. J. Dairy Sci. 81:2866-2873.

Emanuelson, U., P. A. Oltenacu, and Y. T. Grohn. 1993. Nonlinear mixed model analyses of five production disorders of dairy cattle. J. Dairy Sci. 76:2765-2772. 
Emery, R. S., C. K. Smith, R. M. Grimes, C. F. Huffman, and C. W. Duncan. 1960. Physical and chemical changes in bovine saliva and rumen liquid with different hay-grain ratios. J. Dairy Sci. 43:76-82.

Ender, F., I. W. Dishington, and A. Helgebostad. 1971. Calcium balance studies in dairy cows under experimental induction and prevention of hypocalcaemic paresis puerperalis. Z. Tierphysiol. Tierernahr. Futtermittelkd. 28:233-256.

Erdman, R. A., R. D. Shaver, and J. H. Vandersall. 1984. Dietary choline for the lactating cow: Possible effects on milk fat synthesis. J. Dairy Sci. 67:410-415.

Gengelbach, G. P., and J. W. Spears. 1998. Effects of dietary copper and molybdenum on copper status, cytokine production, and humoral immune response of calves. J. Dairy Sci. 81:3286-3292.

Goff, J. P., and R. L. Horst. 1997. Effects of the addition of potassium or sodium, but not calcium, to prepartum rations on milk fever in dairy cows. J. Dairy Sci. 80:176-186.

Holcomb, C. S., H. H. Van Horn, H. H. Head, M. B. Hall, and C. J. Wilcox. 2001. Effects of prepartum dry matter intake and forage percentage on postpartum performance of lactating dairy cows. J. Dairy Sci. 84:2051-2058.

Kimura, K., J. P. Goff, and M. E. Kehrli, Jr. 1999. Effects of the presence of the mammary gland on expression of neutrophil adhesion molecules and myeloperoxidase activity in periparturient dairy cows. J. Dairy Sci. 82:2385-2392.

Kimura, K., J. P. Goff, M. E. Kehrli, Jr., and T. A. Reinhardt. 2002. Decreased neutrophil function as a cause of retained placenta in dairy cattle. J. Dairy Sci. 85:544-550.

Lammers, B. P., D. R. Buckmaster, and A. J. Heinrichs. 1996. A simple method for the analysis of particle sizes of forage and total mixed rations. J. Dairy Sci. 79:922-928.

LeBlanc, S. J., T. H. Herdt, W. M. Seymour, T. F. Duffield, and K. E. Leslie. 2004. Peripartum serum vitamin E, retinol, and betacarotene in dairy cattle and their associations with disease. J. Dairy Sci. 87:609-619.

Minor, D. J., S. L. Trower, B. D. Strang, R. D. Shaver, and R. R. Grummer. 1998. Effects of nonfiber carbohydrate and niacin on periparturient metabolic status and lactation of dairy cows. J. Dairy Sci. 81:189-200.

Muscato, T. V., L. O. Tedeschi, and J. B. Russell. 2002. The effect of ruminal fluid preparations on the growth and health of newborn, milk-fed dairy calves. J. Dairy Sci. 85:648-656.

National Animal Health Monitoring System, Dairy 1996. Part I: Reference of Dairy Health and Management in the United States. USDA/APHIS/VS/NAHMS Centers for Epidemiology and Animal Health, Fort Collins, CO.

National Animal Health Monitoring System, Dairy 2002. Part I: Reference of Dairy Health and Management in the United States.
USDA/APHIS/VS/NAHMS Centers for Epidemiology and Animal Health, Fort Collins, CO.

National Research Council. 2001. Nutrient Requirements of Dairy Cattle. 7th revised edition. National Academy Press, Washington, DC.

Nonnecke, B. J., M. R. Foote, J. M. Smith, B. A. Pesch, and M. E. Van Amburgh. 2003. Composition and functional capacity of blood mononuclear leukocyte populations from neonatal calves on standard and intensified milk replacer diets. J. Dairy Sci. 86:35923604 .

Nonnecke, B. J., R. L. Horst, W. R. Waters, P. Dubeski, and J. A. Harp. 1999. Modulation of fat-soluble vitamin concentrations and blood mononuclear leukocyte populations in milk replacer-fed calves by dietary vitamin A and beta-carotene. J. Dairy Sci. 82:2632-2641.

Ram, L., J. T. Schonewille, H. Martens, A. T. Van't Klooster, and A. C. Beynen. 1998. Magnesium absorption by wethers fed potassium bicarbonate in combination with different dietary magnesium concentrations. J. Dairy Sci. 81:2485-2492.

Randall, W. E., R. W. Hemken, L. S. Bull, and L. W. Douglas. 1974. Effect of dietary sodium and potassium on udder edema in Holstein heifers. J. Dairy Sci. 57:472-475.

Reddy, P. G., J. L. Morrill, H. C. Minocha, M. B. Morrill, A. D. Dayton, and R. A. Frey. 1986. Effect of supplemental vitamin E on the immune system of calves. J. Dairy Sci. 69:164-171.

Scaletti, R. W., D. S. Trammell, B. A. Smith, and R. J. Harmon. 2003. Role of dietary copper in enhancing resistance to Escherichia coli mastitis. J. Dairy Sci. 86:1240-1249.

Smith, K. L., J. H. Harrison, D. D. Hancock, D. A. Todhunter, and H. R. Conrad. 1984. Effect of vitamin E and selenium supplementation on incidence of clinical mastitis and duration of clinical symptoms. J. Dairy Sci. 67:1293-1300.

Stott, G. H., D. B. Marx, B. E. Menefee, and G. T. Nightengale. 1979. Colostral immunoglobulin transfer in calves I. Period of absorption. J. Dairy Sci. 62:1632-1638.

Thilsing-Hansen, T., R. J. Jorgensen, J. M. Enemark, and T. Larsen. 2002. The effect of zeolite A supplementation in the dry period on periparturient calcium, phosphorus, and magnesium homeostasis. J. Dairy Sci. 85:1855-1862

Waterman, R., J. W. Schwalm, and L. H. Schultz. 1972. Nicotinic acid treatment of bovine ketosis. I. Effects on circulatory metabolites and interrelationships. J. Dairy Sci. 55:1447-1453.

Weiss, W. P., J. S. Hogan, K. L. Smith, and K. H. Hoblet. 1990. Relationships among selenium, vitamin $\mathrm{E}$, and mammary gland health in commercial dairy herds. J. Dairy Sci. 73:381-390.

Weiss, W. P., J. S. Hogan, D. A. Todhunter, and K. L. Smith. 1997. Effect of vitamin E supplementation in diets with a low concentration of selenium on mammary gland health of dairy cows. J. Dairy Sci. 80:1728-1737. 